\title{
Non-conventional T-cells in the pathogenesis of alopecia areata: Targeting iNKT10 cells with $\alpha$-galactosylceramide
}

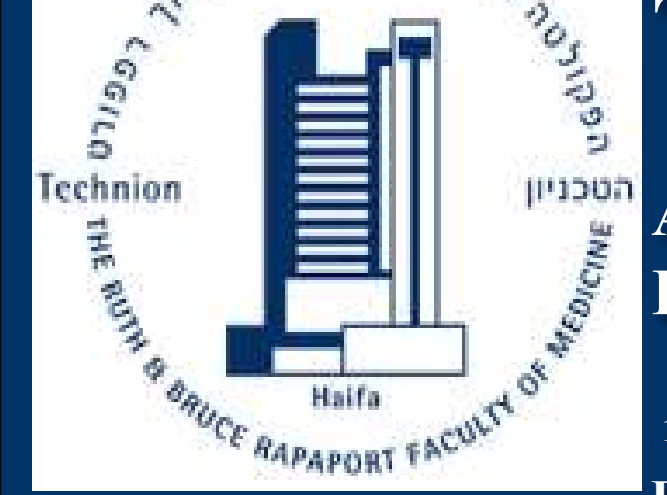

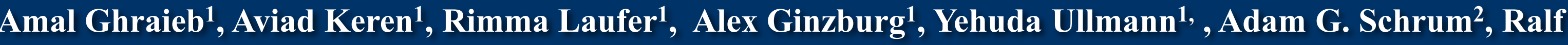 \\ Paus $^{3}$,Amos Gilar'
}

${ }^{1}$ Technion Israel Institute, Haifa, Israel ${ }^{2}$ Department of Immunology, Mayo Clinic College of Medicine, Rochester, Minnesota, USA, ${ }^{3}$ Centre for Dermatology Research Centre, University of Manchester, Manchester, UK

\section{INTRODUCTION}

Alopecia areata (AA) is a common, $\mathrm{T}$ celldependent, organ-specific autoimmune disease that predominantly attacks growing hair follicles (HF) that have lost their relative immune privilege (1). While a central, AA-promoting role of NKG2D+CD8+ T cells is now wellappreciated, other cells likely contribute to the pathobiology of AA (2). Since iNKT cells, the prototype of 'unconventional' $T$ cells, have become a recent focus of interest in autoimmune disease research (3), we wished to clarify whether they play any role in human AA, utilizing the best currently available humanized mouse model for AA (1). Recently, impressive regulatory effects of iNKT10 were described. Moreover, the authors demonstrated expansion of iNKT10 by repeated stimulation with the most potent glycolipid antigen, alpha galactosylceramide ( $\alpha$-GalCer) (4)

\section{The aim}

To probe the effects of $\alpha$-GalCer on experimentally induced human AA in vivo.

\section{METHODS \& MATERIALS}

Mice. 90 SCID/Beige mice, 8-12 weeks of age, were used and raised in a pathogen-free facility in accordance with institutional guidelines for animal use.

Humanized Mouse Model. 13 healthy donors aged $43 \pm 10$ years without a personal or family history of AA were enrolled in the study. $3 \mathrm{~mm}$ punch biopsies were obtained from the scalp and peripheral blood mononuclear cells (PBMCs) isolated from the same donors.

Cell Culture to Induce NK Activity and Receptors. The PBMCs were cultured with 100 $\mathrm{U} / \mathrm{ml}$ of IL-2(IL-2/PBMCs) in medium. After 14 days, $7 \times 10^{6}$ of these cells were injected intradermally into human explants on SCID/Beige mice.

RESULTS

Figure 1
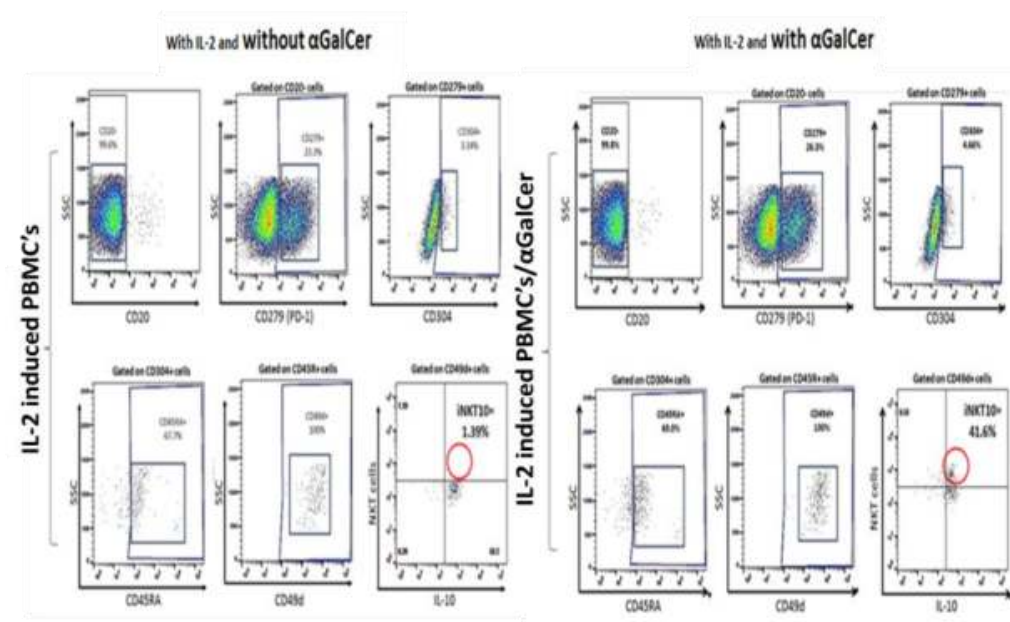

Figure 1. Flow cytometry analysis of NKT10 cells. Representative flow cytometry dot plots visualize iNKT10 cells (red circle): $41.6 \%$ of NKT expressed markers by PBMCs, which had been cultured with IL-2 and Galcer versus only $1.39 \%$ in group cultured without $\alpha$-Galcer. These markers were found to be increased in iNKT10 and are as follows: CD49d, CD45RA, CD279, CD304 and negative for CD20.
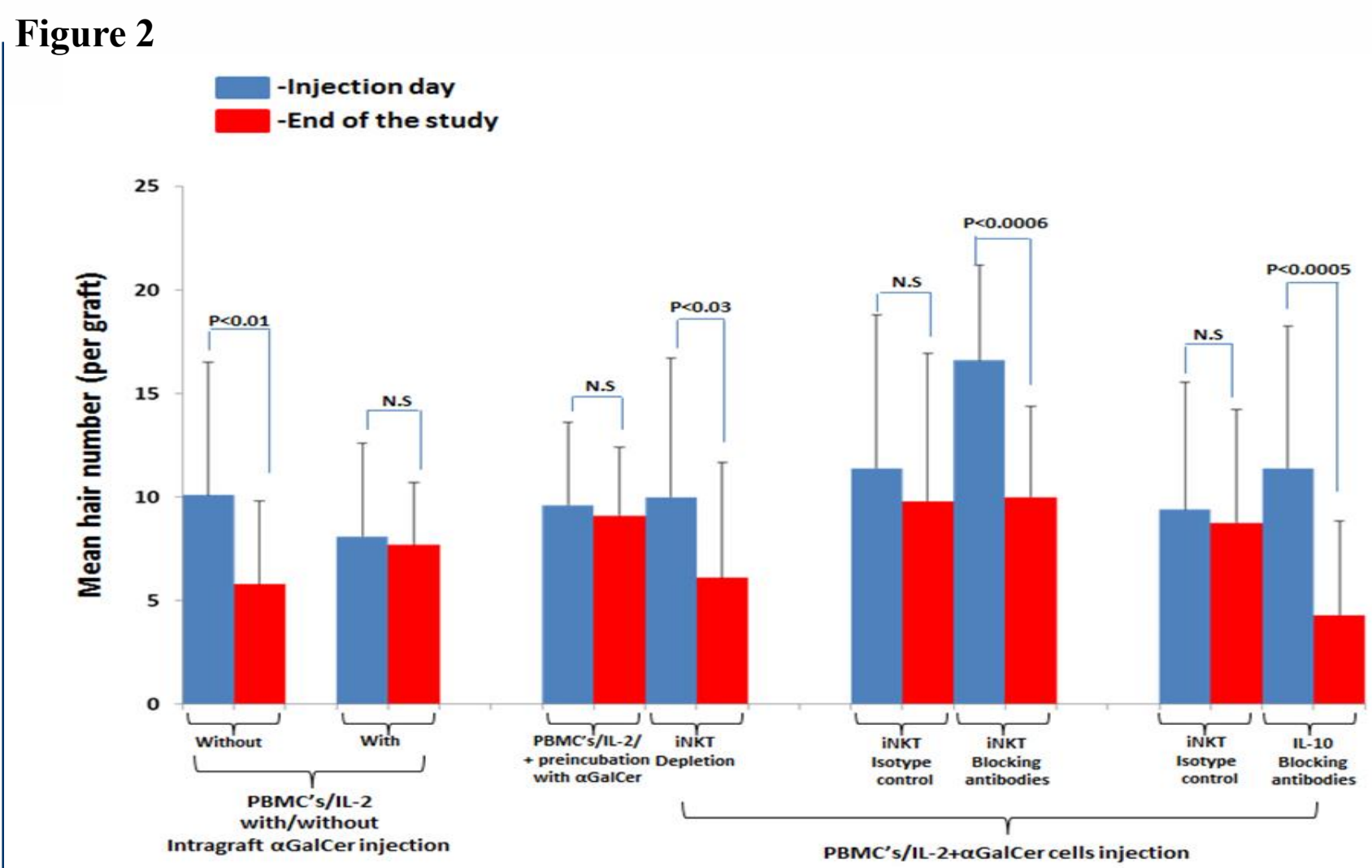

Figure 2- Administering $\alpha$-GalCer to IL-/PBMCs prior to their injection into human scalp skin grafts prevented the development of AA lesions. When injection of $\alpha$-GalCer into grafts was performed subsequent to PBMC injection, development of AA lesions was prevented. The protective effect of $\alpha$-GalCer was inhibited by adding NKT cell blocking Abs during IL-2/PBMCs, or by depleting of NKT cells from the cultured cells prior to graft injection. Similarly, significant hair loss was observed in $\alpha \mathrm{GalCer}+\mathrm{IL}-2 / \mathrm{PBMC}$-injected grafts that were subsequently injected with anti-IL-10 blocking antibodies $(\mathrm{p}<0.0005)$

\section{Figure 3}
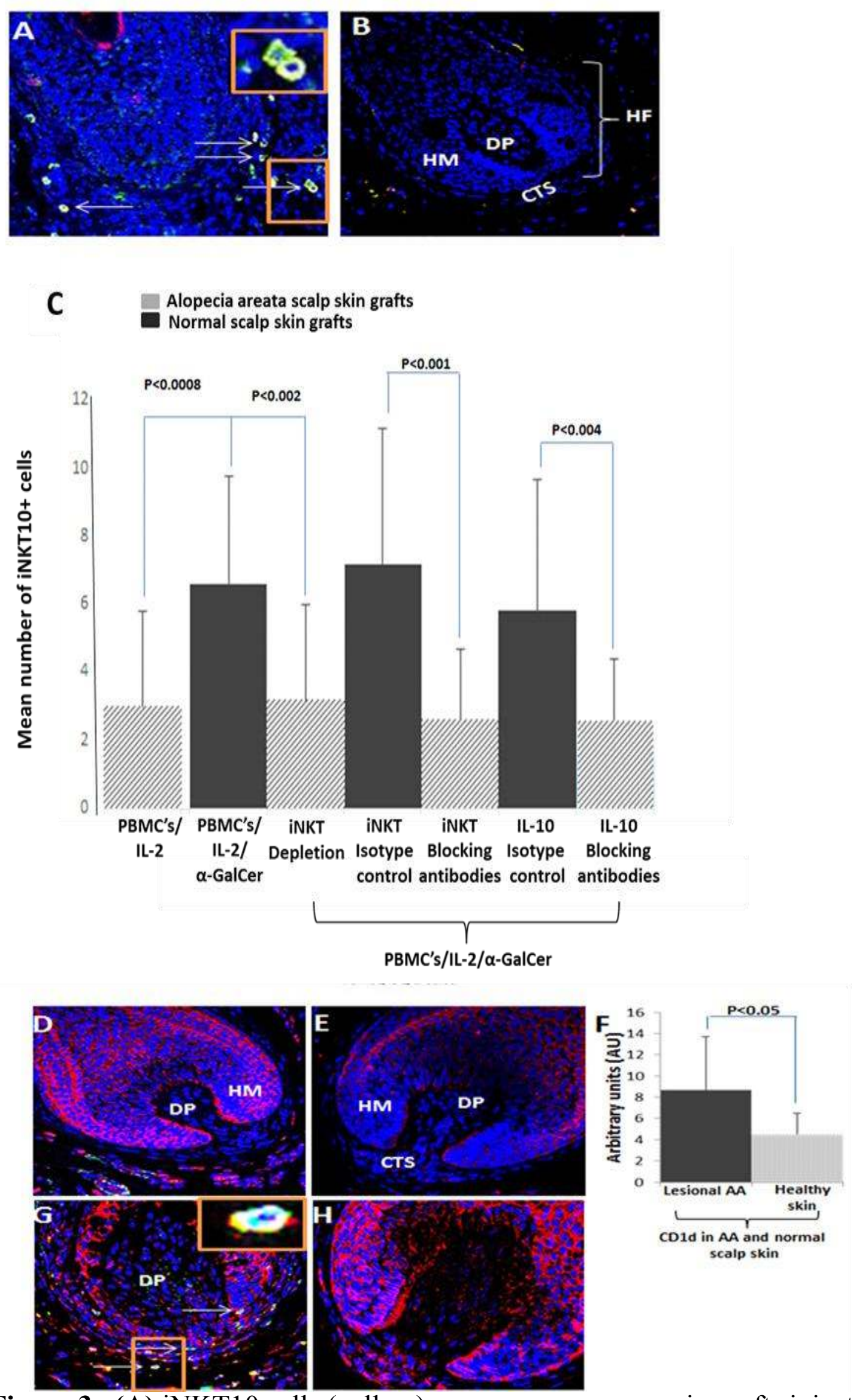

Figure 3. (A) iNKT10 cells (yellow) were more numerous in grafts injected with $\alpha$ GalCer + IL-2 $\backslash$ PBMCs than in grafts (B) injected with IL-2/PBMCs; $(p<0.0008)$. (C) NKT10 cell counts demonstrates an inverse correlation with the development of AA lesions. (D) Stronger CD1d expression by the follicular epithelium in the AA patient was observed compared (E) with that of the control volunteer. (F) ICH analysis of CD1d expression by lesional HF epithelium of AA patients as compared to HFs of normal scalp skin of normal volunteers. (G) Colocalization of CD1d and IL-10 around the HF appeared stronger in grafts injected with $\alpha$-GalCer + IL-2/ PBMCs than $(\mathbf{H})$ in grafts injected with IL-2/ PBMCs.
Figure 4

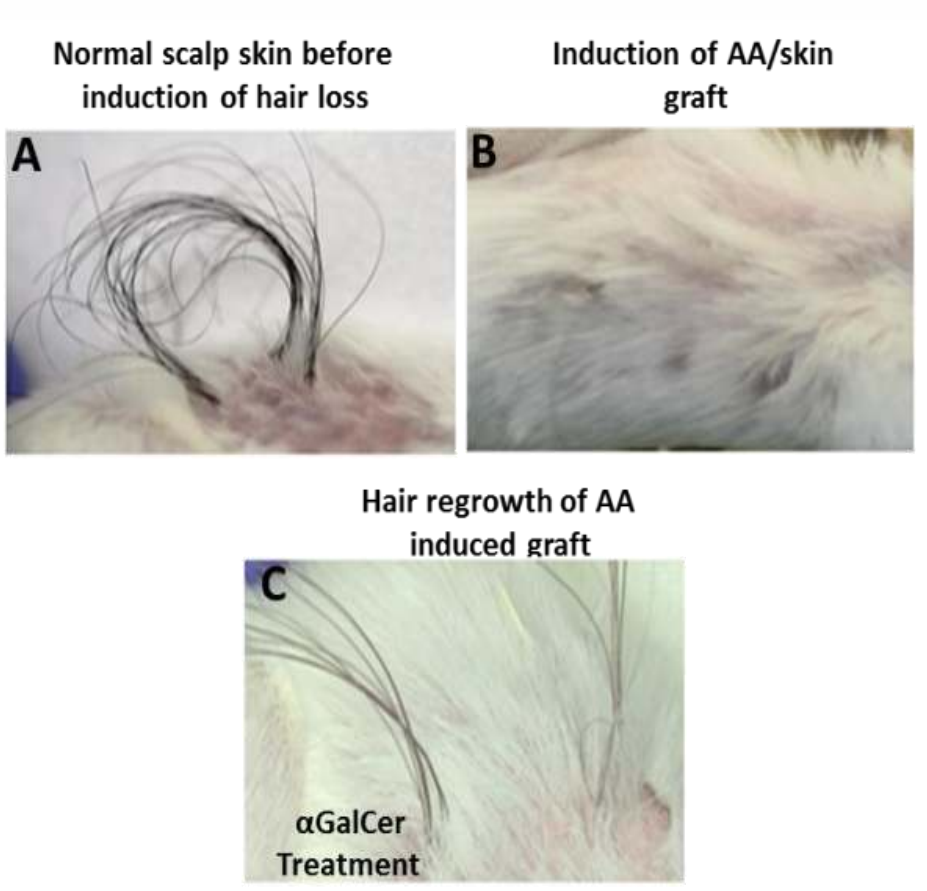

D

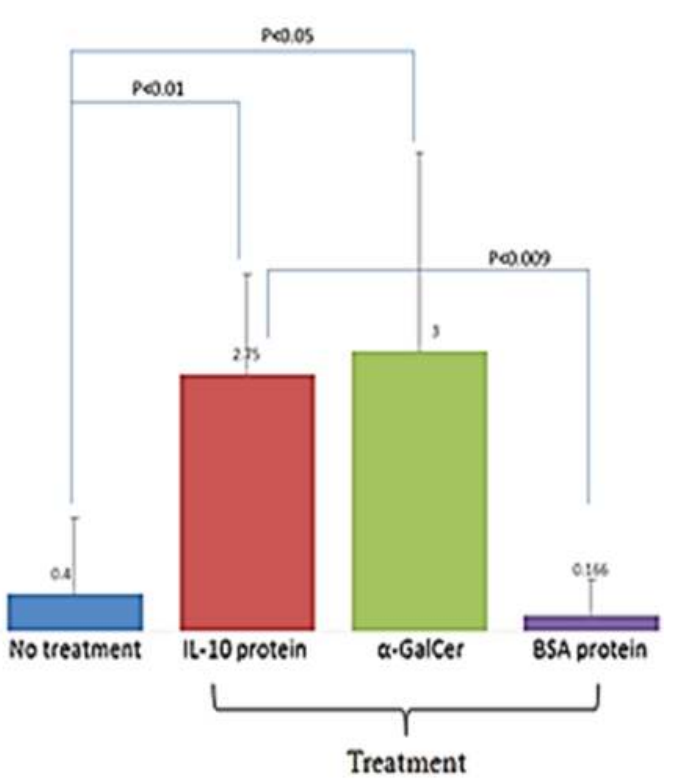

Figure 4. Therapeutic effect of exogenous IL-10 and $\alpha$-GalCer in pre-established AA lesions in humanized grafts. (A) Prior to induction of experimental AA (B) Injection of IL-2/PBMCs caused hair loss. (C)Treatment with $\alpha$-GalCer induced hair re-growth. (D) Quantitative data demonstrate a significant increase in the number of hair in the preinduced AA lesions following treatment with either IL-10 or $\alpha$-GalCer $(p<0.01, p<0.05$, respectively) when compared with control BSA treatment $(\mathrm{p}<0.009)$

CONCLUSIONS

1. The study identifies iNKT10 cells as novel key players in human AA.

2. $\alpha$-GalCer could become a therapeutic alternative to, and/or could complement, therapy with non-specific JAK-STAT inhibitors

\section{References}

1. A. Gilhar, A. et al. N. Engl. J. Med. 366 (2012)1515-1525.

2. M. Bertolini, F.et al. PLoS One. 9 (2014) e94260.

3. D.I. Godfrey, et al. Nat. Immunol. 16 (2015) 1114-1123.

4. D. Sag, et al. J. Clin. Invest. 124 (2014) 3725-3740. 